\title{
THE CORTICAL PROJECTION OF THE MEDIAL GENICULATE BODY
}

BY

\author{
H. H. WOOLLARD AND A. HARPMAN
}

From the Institute of Anatomy, University College, London

(Received 28Th SePtember, 1938)

THERE are but few accounts of the study of the cortical distribution of the auditory radiation by means of lesions of the medial geniculate body. Apart from clinico-pathological studies in man, most of the investigations have been made by means of cortical stimulation and ablation.

In man and the monkeys there is general agreement that the auditory radiation ends in the superior temporal gyrus within the Sylvian fissure. The only point at issue is how much, if any, of the exposed surface of this convolution is reached by the radiation. The results, however, in the common laboratory animals-the dog, the cat, and the rabbit-are uncertain and discrepant.

Ferrier (1876) studied the cortical localization of hearing in monkeys, dogs, cats, and rabbits both by stimulation and extirpation. Amongst the several responses that occurred from stimulation he regarded pricking of the ears as the one most indicative of the auditory area. Bilateral cortical extirpation was performed, and taking every precaution to prevent arousing the animal's awareness through some other channel, hearing was tested by sounds made in various ways. Ferrier placed in the cat the auditory receptive zone, to which he gave in his account the number 14, in the superior part of the second arcuate gyrus, or gyrus ectosylvius medius, i.e. between the upper end of the pseudosylvian and the suprasylvian sulcus.

Munk $(1878,1881)$ removed in dogs the posterior portions of the second, third, and fourth arcuate gyri (or posterior suprasylvian and posterior lateral gyri), i.e. the cortical region immediately in front and behind the posterior limb of the superior sylvian fissure (the post-sylvian fissure of Owen). The dog is described as being in such a state that for three or four weeks after the operation it is deaf. It then becomes able to hear, but does not understand what it hears. In the cortical zone immediately above the pseudo-sylvian sulcus Munk placed " tactile awareness" of the ear. Mann (1896) stimulated the cortex in cats and rabbits. The area from which movements of the ear were most easily elicited corresponded with Ferrier's localization of the auditory zone.

Luciani (1884), who was very critical of the work of Munk, used, however, 
the same methods on the same animals and concluded that the auditory area was much more extensive, reaching upwards into the parietal, downwards into the hippocampal, and backwards into the visual zone.

E. A. Schäfer (1888), repeated the experiments of Ferrier in the macaque monkey. He made bilateral ablations of the cortex, and, to be quite sure, removed still more temporal cortex than did Ferrier. At first the monkeys so operated upon seemed quite idiotic ; later, as they recovered from the operation, it would become obvious that they could still hear. Schäfer also asserted
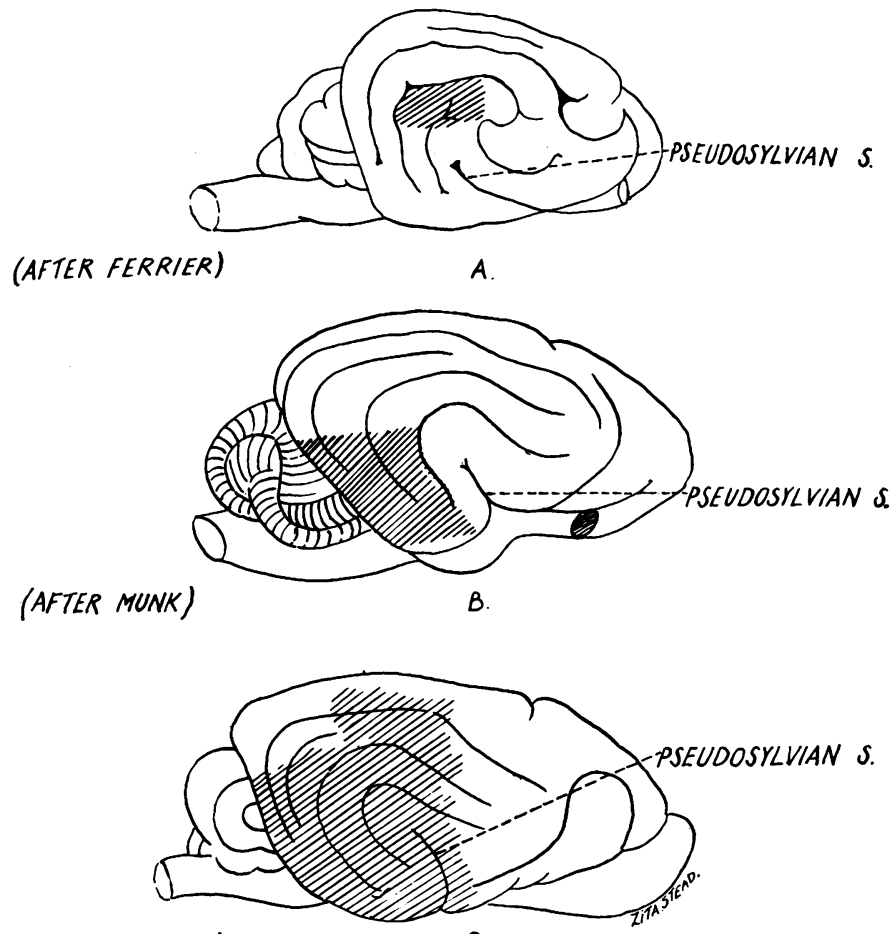

(AFTER LUCIANI)

c. Fig. 1.-The cortical auditory receptive area in $\mathrm{A}$ the cat and $\mathrm{B}$ and $\mathrm{C}$ the dog, after various

that when he stimulated the cortex he could not satisfy himself that pricking of the ears or associated reactions had any special relation to the superior temporal gyrus.

von Monakow (1895) removed in new-born kittens a cortical area which extended from the anterior ectosylvian fissure in front to the caudal margin of the hemisphere behind. Six months later atrophy over a considerable area, including the whole of the homolateral medial geniculate body, was found histologically.

This conflict of opinion suggests that the methods of stimulation and the search for functional deficiency after extirpation are not altogether suitable for the precise delimitation of the audito-sensory receptive field. It would seem, therefore, that little value could be given to the work of Larionow (1899), 
who published a map of the auditory receptive area in the dog based upon its inability to hear a series of musical notes after the ablation of small cortical areas in the region of the posterior part of the suprasylvian fissure.

These ablation experiments upon dogs and other animals were repeated as newer methods became available. Amongst others the method of conditioned reflexes was used. Kalischer (1907), Swift (1910), Zeliony (1913), and Karplus and Kreidl (1914) all concluded that neither bilateral nor even complete removal of the cortex of both sides produced deafness in dogs and monkeys.

Various authors have claimed that they have confirmed Ferrier's localization of the auditory receptive zone by electrical and oscillographic methods. Leading off from this part, Larionow (1899), Kornmüller (1937), Bremer (1937), et al. have made electro-encephalograms from the exposed cortex in man and animals. From the comments made by Walters (1937) it seems that the deflections obtained from the cortex are so small that they cannot easily be disentangled from those of physical origin. It is apparently too soon to use this method as a means of anatomical exploration of the cortex. The method of cortical ablation permits of anatomical study of neural connections by retrograde chromatolytic effects. The Marchi method, of course, can be used to trace the degeneration of any tracts originating in the ablated area. Ohnishi (1931) made lesions in the cortex and in the medial geniculate body of rabbits. $\mathrm{He}$ describes ascending and descending fibre connections between the two structures. The tract from the medial geniculate body is said to end in the superior, middle, and inferior gyri of the rabbit's temporal cortex. In the absence of any figure depicting the area of termination precisely, this statement must be taken to mean that all parts of the temporal area as defined histologically receive the geniculo-cortical fibres. Mettler (1935) believes that a descending tract starts from the lateral surface of the superior temporal convolution and ends in the medial geniculate body. Our own experiments are of such a nature that they cannot be used to determine the existence of descending tracts to the medial geniculate body. Clark and Boggon (1935), Le Gros Clark (1936), Walker (1937), and Rundles and Papez (1938) et al. have investigated the effects upon the cells of the medial geniculate body after lesions of various parts of the temporal cortex in the monkey. By this method it has been shown that the greatest part of the medial geniculate body is connected with the superior temporal gyrus within the lips of the sylvian fissure. The only point at issue between these investigators concerns the problem whether a slender collection of large nerve cells (the nucleus parageniculatus), for the most part internal to the medial geniculate body, is or is not connected with the temporal cortex. Our own experiments have been carried out in such a way that they are of no use in solving the connection of the nucleus parageniculatus.

\section{Present Experiments}

In the course of producing electrolytic lesions in various parts of the central nervous system in a series of cats, it so happened that in two cats the lesion was so placed that the medial geniculate body alone was virtually destroyed. The 
placing of the electrolytic needles in the brain was done by means of the ClarkeHorsley stereotaxic instrument, while the animals were under ether anæsthesia. The animals were killed twelve days after the lesion was made. The brains were removed and studied by the Marchi method.

The area destroyed by electrolysis measures transversely $2.5 \mathrm{~mm}$. and occupies the anterior and medial aspect of the medial geniculate body. Thus the lesion is so placed that all of the geniculo-cortical fibres will be destroyed at their commencement, together with a part of the oro-dorsal nucleus of the medial geniculate body. The lesion being situated in the more medial part of

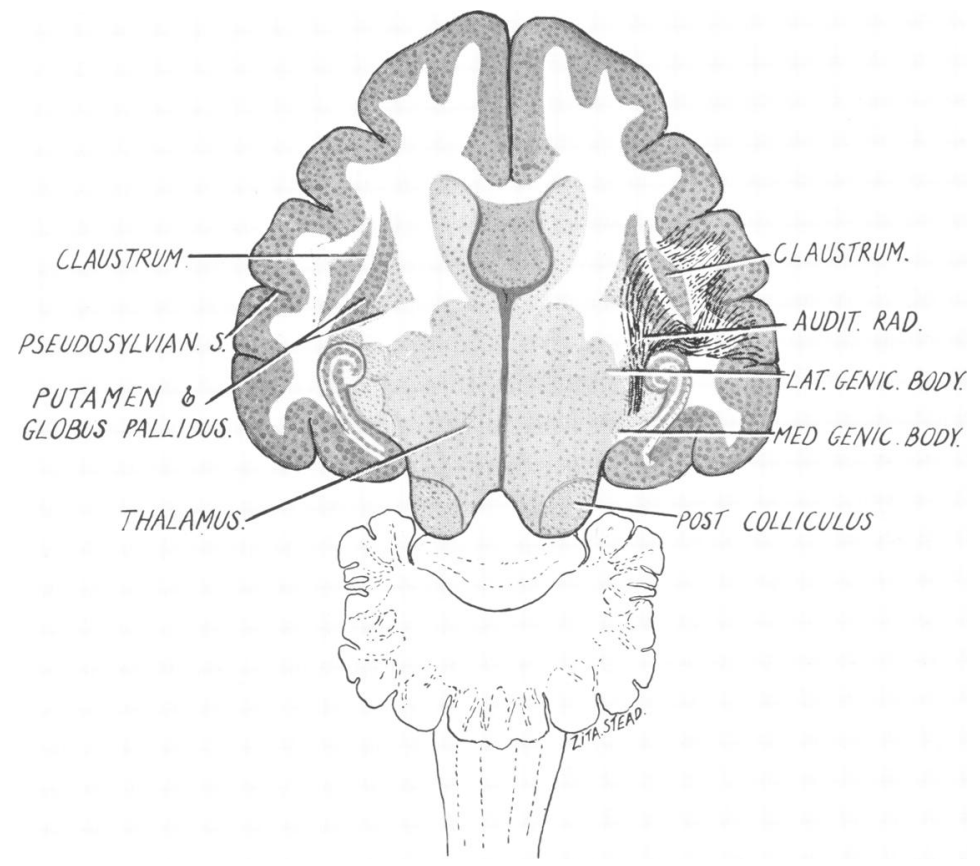

Fig. 2.-Scheme of the path of the auditory radiation in the cat's brain.

the medial geniculate body, it is possible that the ventral nucleus of the thalamus and the medial lemniscus may be slightly injured. Careful superimposition of the extent of the lesion upon the appropriate drawings in Winkler's Atlas (1914), and upon our own series of cats' brains stained for cell masses, together with a study of the fibre degeneration in the experimental brains themselves, shows that the lesions could have injured the thalamus only very slightly.

\section{Observations}

The study of the Marchi preparations may be described thus : the lesions and observations being almost identical, both experiments are described together.

Cortical fibres; Degenerated fibres start from the place of the lesions and as they are traced forwards they come to occupy a field which is immediately caudal to the lateral geniculate body. While still in this position it becomes 
possible for them to enter the white matter of the cerebrum. It is to be remembered that the rotation and displacement of the geniculate bodies which occurs in man owing to the great development of the pulvinar has not happened in the cat. The lateral geniculate body is dorsal and anterior to the medial geniculate body. The fibres fan out as they enter the white matter; those coming from the more lateral part of the medial geniculate lie more lateral in the fan and reach the more caudal part of the cortex, the more medial

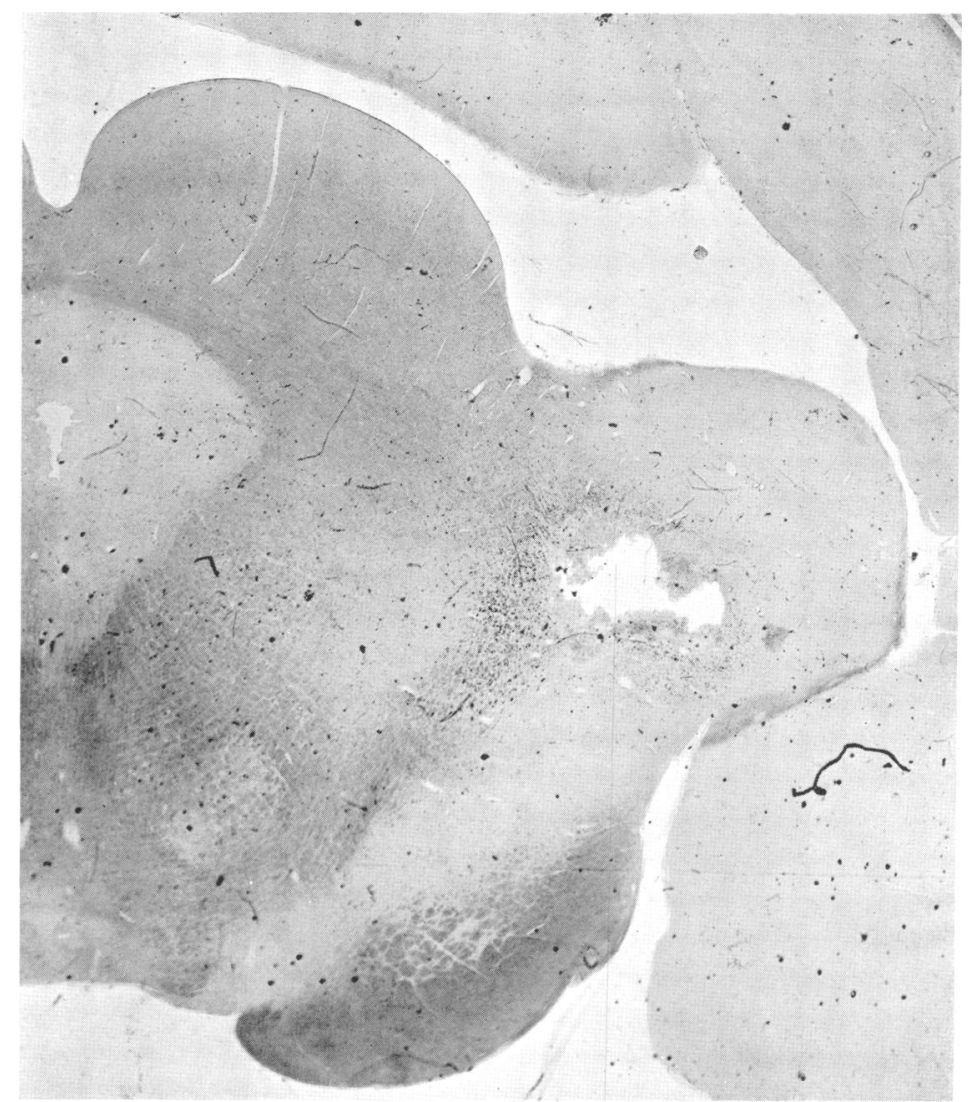

Fig. 3. - Photomicrograph of lesion in cat's brain at level of medial geniculate body. $\quad \times 13$.

lie in the front part of the fan and reach the anterior part of the cortex. The fibres from the more dorsal part of the medial geniculate reach the upper and those from the more ventral the lower part of the cortex. There is thus regularity and uniformity in the arrangement of the geniculo-cortical fibres, so that a kind of point-to-point relationship exists between the medial geniculate body and the cortex - a suitable anatomical basis for precise localization in the two systems.

The fibres from the medial geniculate body as they enter the white matter of the brain are covered by the optic tract as it nears the lateral geniculate body. The ventral fibres from the anterior part of the medial geniculate body traverse 
the peduncle ; the others enter immediately the internal capsule, where they lie below the optic radiation.

Upon entering the substance of the brain some of the more anterior of the

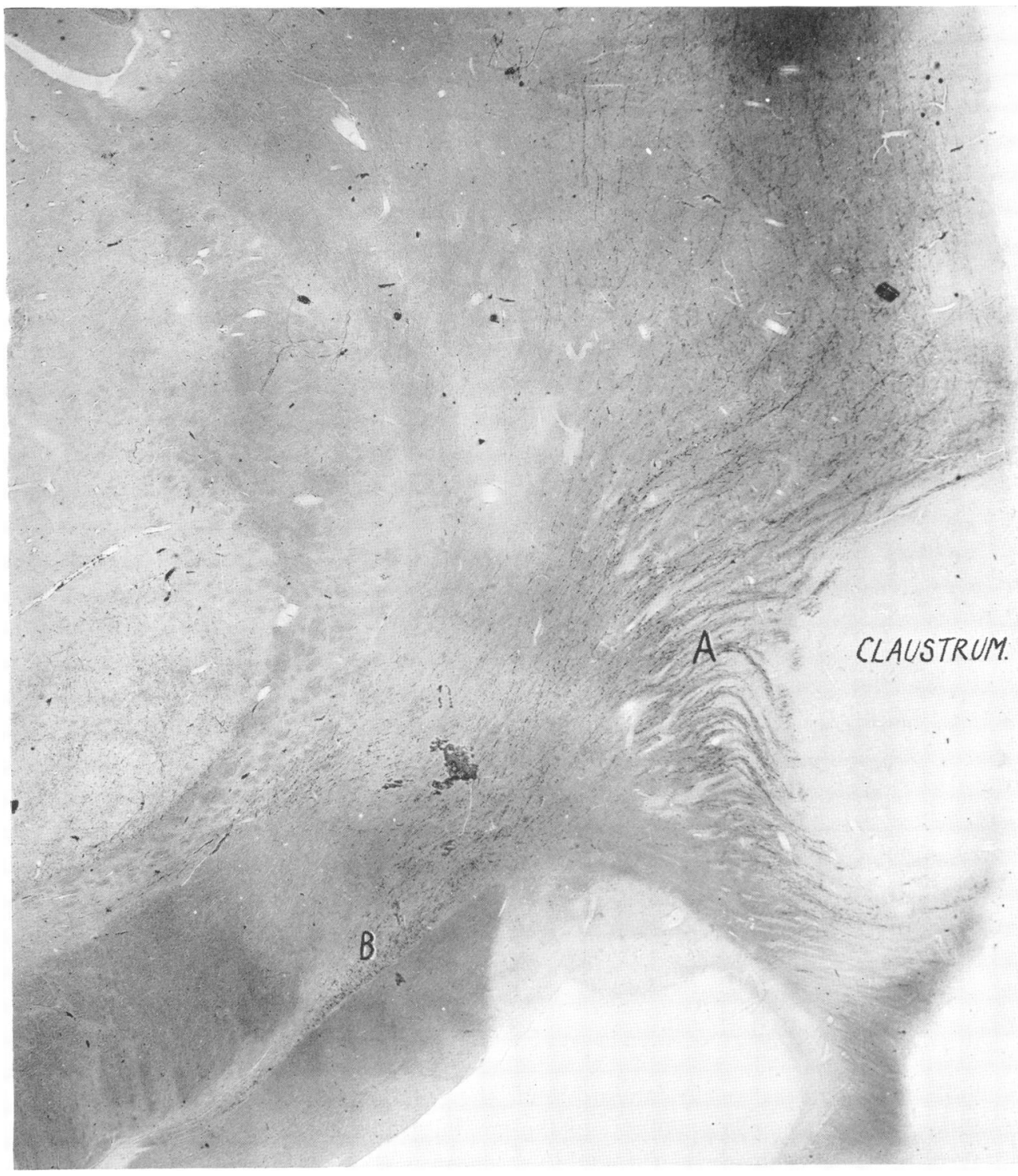

Fig. 4.-Photomicrograph of degenerated fibres in cat. A. Auditory radiation passing through globus pallidus and putamen above and below claustrum. B. Part of auditory radiation lying between peduncle and optic tract. $\times 13$.

radiating fibres traverse the globus pallidus and the putamen, reaching the posterior part of the claustrum. They arch backwards slightly as they travel round the posterior end of the claustrum to reach the cortex. Many of the fibres reach the cortex by passing caudal to the globus pallidus, putamen and 
the claustrum. The upward spread of the fibres becomes much more acute as the cortex is approached, the most dorsal fibres running parallel with the cortex to reach their destination.

The extent of the cortical area in which these fibres terminated was defined by reconstructing the surface of the brain from serial drawings. It is as follows : posteriorly the boundary is the posterior ectosylvian sulcus; superiorly the

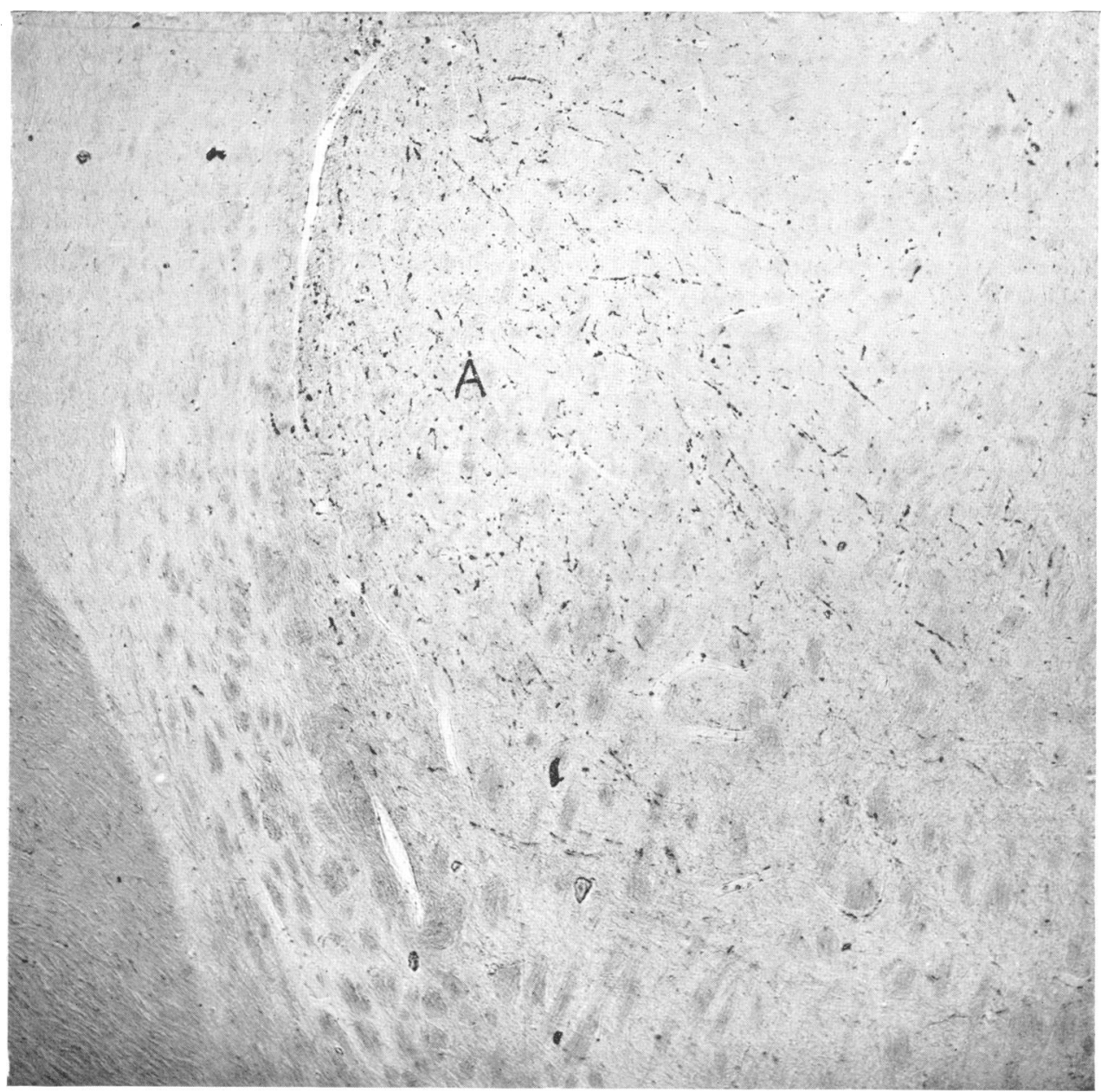

Fig. 5.-A. Degenerated fibres in the lateral part of the pars externa of ventral nucleus of thalamus, which have come from lateral part of mesial fillet. $\times 36$.

suprasylvian sulcus; anteriorly the anterior ectosylvian sulcus, though superiorly the degenerated fibres pass beyond this fissure slightly and below do not quite reach it ; and below the area ends a short distance above the rhinal fissure.

Involvement of other Structures.-There is no degeneration in Gudden's commissure. There is some reason to suppose that the fibres which form this commissure start from the cells of the ventral nucleus of the medial geniculate. 
The lesions are so placed in these cats that they might be expected to involve at least some of these cells. The absence of degenerated fibres raises a slight doubt as to the correctness of the above view of the origin of Gudden's commissure.

In both experiments there is some slight scattered degeneration in the lateral portion of the ventral nucleus of the thalamus adjacent to the lesion. This is explained by the fact that at the actual site of the lesion a few lateral fibres of the medial lemniscus were involved. These degenerated fibres occupy the lateral portion of the pars externa of the ventral nucleus of the thalamus.

The electrolytic needles reached the medial geniculate body by passing horizontally forwards from the occipital region in the vicinity of the foramen magnum. In doing so an injury sharply localized to the nucleus cuneatus occurs in each cat. From this nucleus degenerate fibres can be traced in the

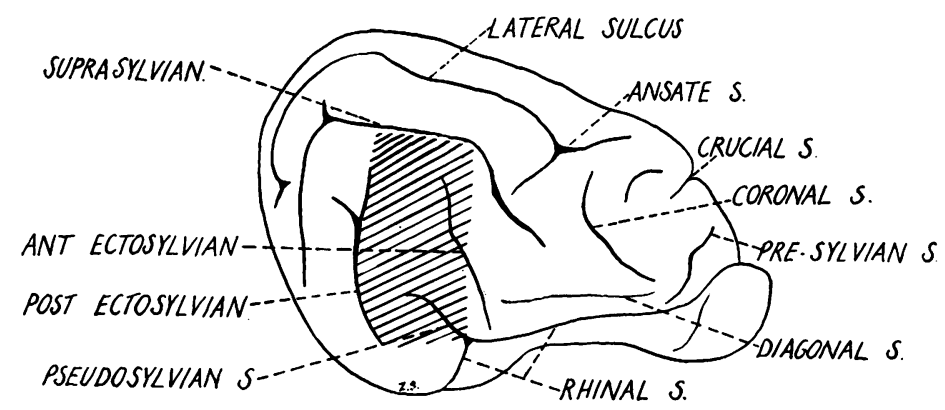

Fig. 6.-The cortical audito-sensory area in the cat as determined by the present experiments.

internal arcuate group across the middle line to the opposite side where they occupy a ventral position. A few go to the cuneate nucleus of the opposite side ; the rest pass medially and assemble about the inner extremity of the inferior olive. Eventually they can be traced to the more medial part of the pars externa of the ventral nucleus of the thalamus.

Two other negative statements perhaps should be made. A geniculothalamic tract has been postulated as a result of the examination of normal material : Rioch (1931), Glorieux (1929). The present Marchi preparations are appropriate for determining the existence of such a tract. None has been found.

The fibres which compose the geniculo-cortical tract from the medial geniculate body are entirely homolateral and none reach the cortex of the opposite side.

\section{Comment}

The limitations of these experiments have already been referred to. The lesions have been so placed that the fibres belonging to the region of the medial geniculate body described as the hilus have been severed.

Winkler (1921) has described the fibres of this hilus as containing not only the geniculo-temporal fibres, but also geniculo parietal and occipital fibres $\mathrm{He}$ describes the position of these in the field of Wernicke and their inter- 
mingling with the optic radiation. In addition he says there are cortical components in this region which have come by way of the inferior or posterior brachium from the posterior quadrigeminal body. If these fibres exist in the cat and occupy the positions assigned to them by Winkler, they must have been included in the lesions and their cortical distribution would have been disclosed in the Marchi preparations. Only geniculo-temporal fibres have been found. These experiments in the cat do not, of course, decide against the origin of cortical fibres from the posterior quadrigeminal body. However, experiments upon the guinea-pig in which the posterior quadrigeminal body was destroyed show no degenerated fibres going to the cortex. We conclude that fibres from the medial geniculate and posterior quadrigeminal body to other parts of the cortex do not exist.

The actual cortical area assigned to the auditory radiation is bounded on all aspects by fissures constant in the cat's brain. If we assume that the meaning of fissures is to be found in the limit they prescribe to homogeneous functional areas, then it is satisfactory to such a theory that the auditory area is so circumscribed. The precise localization of the auditory area is obviously of importance in the study of the problem of fissuration in general.

The strict homolaterality of the auditory radiation makes it necessary to assume that the bilaterality of hearing depends upon the crossing of fibres either at the level of the medial geniculate bodies or in the course of the auditory tracts which reach these.

It might be expected that the auditory receptive area having in general a uniform sensory receptive function might be constructed in a uniform histological manner. Reference to the literature upon this matter reveals much discrepancy and difficulty. As a result of these experiments and of microscopic studies of the cat's cortex we are able to assert that it has got a uniform, easily recognizable histological pattern. It is hoped to make a subsequent communication upon this problem of cytoarchitectonics.

In the list of the findings reference has been made to certain lesions of the mesial fillet, one of its lateral fibres in the mid-brain and the other in the cuneate nucleus. From the course of the degenerated fibres it can be inferred that the fibres from the cuneate nucleus which represent the upper or fore part of the body occupy the medial part of the mesial fillet, a position they acquire as they cross the middle line in the medial arcuate fibres. When the pars externa of the ventral nucleus of the thalamus is reached, these fibres end in its medial part. This observation is corroborated by the injury of the lateral part of the mesial fillet, the degenerated fibres of which go to the lateral part of the pars externa of the ventral nucleus of the thalamus. Le Gros Clark (1936 $b$ ) has presented the results of his own experiments upon the termination of the mesial fillet in the thalamus, and analysed the literature which bears upon this problem. It will be found that the results we have recorded are in agreement with the conclusions of Le Gros Clark.

In man and monkeys Pfeiffer (1920) and Poliak (1932) both describe the spiral twist which occurs in the fibres of the auditory radiation near the cortex, and the angulation of the fibres at their commencement due to the ventro- 
lateral displacement of the medial geniculate body. Neither the spiral twisting of the fibres nor the angulation is present in the auditory radiation of the cat. The only obstacle the radiation encounters in the cat is the claustrum. The fibres penetrate readily the globus pallidus and the putamen. They go above or below or behind the claustrum, but not through it. As already mentioned, many of the fibres go behind the claustrum.

\section{Summary}

The distribution of the auditory radiation has been studied in the cat by the Marchi method after electrolytic lesion at its origin from the medial geniculate body.

It has a strict homolateral distribution to the cortical area, bounded in front approximately by anterior ectosylvian fissure, behind by the posterior ectosylvian, above by the suprasylvian fissure, and below ending a short distance above the rhinal fissure. It is traversed axially by the pseudo-sylvian fissure.

There is no angulation or spiral twisting of the fibres of the auditory radiation.

The termination in the pars externa of the ventral nucleus of the thalamus of the mesial fillet is such that the fasciculus cuneatus occupies its more medial part.

\section{REFERENCES}

Bremer, F. (1937). C.R. Soc. Biol., 124, 842.

Clark, W. E. Le G. (1936a). J. Anat., 70, 447. (1936b). Ibid., 71, 7 .

and Boggon, R. H. (1935). Philos. Trans., B., 224, 313.

Ferrier, D. (1876). The Functions of the Brain. London.

Glorieux, P. (1929). J. Belge Neurol. Psychiat., 29, 525.

Kalischer, O. (1907). Sitzungsbericht preuss. Akad. Wissenschaften., 204.

Karplus, J. P., and Kreidl, A. (1914). Arch. Anat. Physiol., Lpz., 155.

Kornmüller, A. E. (1937). Die bioelectrischen Erscheinungen der Hirnrindenfelder, 46. Thieme.

Larionow, W. E. (1899a). Arch. Physiol., 76, 608.

- $(1899 b)$. Neurol. Zbl., 18, 767 .

Luciani, L. (1884). Brain, 7, 145.

Mann, G. (1896). J. Anat. Physiol., 30, 1.

Mettler, F. A. (1935). J. comp. Neurol., 63, 25.

Monakow, C. (1895).: Arch. Psychiat., 27, 1.

Munk, H. (1881). Über die Funktionen der Grosshirnrinde. Berlin.

Ohnishi, G. (1931). Okayama-Igakkai-Zasshi, 43, 1959.

Pfeiffer, R. A. (1920). Saechsische Akad. Math. Phys. Abhandlungen, 37, 1.

Poliak, S. (1932). The Main Afferent Fiber Systems of the Cerebral Cortex in Primates, 81. University California Press, Berkeley.

Rioch, D. M. (1931). J. comp. Neurol., 53, 319.

Rundles, R. W., and Papez, J. W. (1938). Ibid., 68, 267.

Schäfer, E. A. (1888). Brain, 10, 362.

Swift, W. B. (1910). Neurol. Zbl., 29, 686.

Walker, A. E. (1937). J. Anat., 71, 319.

Walter, W. G. (1937). Proc. roy. Soc. Med., 30, 579.

Winkler, C. (1921). Manuel Neurol., 1, 324. Haarlem.

- and Potter, A. (1914). An Anatomical Guide to Experimental Researches on the Cat's Brain. Amsterdam.

Zeliony, G. P. (1913). C.R. Soc. Biol., 74, 707. 